\title{
Female rats prefer to mate with dominant rather than subordinate males
}

\author{
W. J. CARR, KENNETH R. KIMMEL, STEVEN L. ANTHONY, \\ and DAVID E. SCHLOCKER \\ Beaver College, Glenside, Pennsylvania 19038
}

\begin{abstract}
An earlier experiment revealed that among pairs of male rats that compete for access to a receptive female, the dominant male enhances its own chances of reproductive success by inhibiting the subordinate's mating behavior. In the present experiment, 12 females each mated with a pair of males until the males had established a dominant-subordinate relationship. Shortly thereafter, in a two-choice mating preference test, the females exhibited a reliable preference $(\mathrm{p}<.01)$ to mate with the dominant male rather than with the subordinate male. Considered together, these two experiments suggest that success in intermale aggression enhances a male's fitness in two ways. Dominant males (1) compete successfully for females by actively inhibiting the mating behavior of subordinates and (2) are more attractive to females than are subordinates. The stimulus basis of the preference of females for dominant males remains to be established.
\end{abstract}

Among most rodents, the females make a much greater parental investment and therefore constitute a limited resource for which the males must compete (Dewsbury, 1981; Doty, 1974). Indeed, Thor and Carr (1979) showed that pairs of sexually experienced male rats fight vigorously when housed with a receptive female and that the dominant male actively inhibits the subordinate's mating behavior so that the dominant male is more likely to impregnate the female.

In view of recent evidence that female rats exert considerable control over the male's mating behavior (Doty, 1974), it was of interest to learn whether females respond differentially to dominant vs. subordinate males. To determine this, we permitted 12 pairs of males to compete for access to a receptive female until a dominantsubordinate relationship had been established. Then, in a mating preference test during which the males were restrained on leashes, we observed the female's tendency to approach and mate with each male.

\section{METHOD}

\section{Subjects}

Twelve female rats (Long-Evans) served as subjects and 33 males (Long-Evans) provided the females with mating experience prior to testing and/or served as potential mating partners during testing. Except as noted below, the animals were housed individually in wire-mesh cages (Wahmann, Inc., LC/75A) in which Lab Chow pellets and water were available constantly. The females were ovariectomized prepuberally and rendered receptive, when necessary, by three subcutaneous injections (at 72 , 48 , and $24 \mathrm{~h}$ before testing), each containing $.02 \mathrm{mg}$ estradiol in

We thank Denise Beard and Jean Carr for technical assistance and Arthur S. Watnick of the Schering Corporation for the estradiol. Requests for reprints should be addressed to the first author.
$.2 \mathrm{ml}$ sesame oil, and one injection (at $6 \mathrm{~h}$ ) of .25 progesterone in $.25 \mathrm{ml}$ sesame oil.

\section{Apparatus and Procedure}

Beginning at $130-150$ days of age, each female received three weekly mating experiences, each lasting $40 \mathrm{~min}$. At the outset of each mating experience, the female was housed with a male in a topless rectangular enclosure $(50 \times 60 \times 90 \mathrm{~cm})$, lined with pinewood chips. A different male was used for each female's three mating experiences. In every case, the male copulated until at least one ejaculation occurred during at least two of the mating experiences, thus ensuring that both the males and females were, in fact, sexually experienced.

One week later, each female received a single mating preference test, conducted in the same enclosure in which it had received its mating experiences. Shortly before the test, the female and two males were placed in the enclosure in which both mating behavior and intermale aggression ensued. The experimenters observed the aggressive behavior of each male until a dominant-subordinate relationship had been established. A given male was said to be dominant if, on three successive occasions, it initiated (1) a bite-kick attack that ended with the other male immobilized in prone or supine position or (2) a hip-thrust threat that evoked a sideways pose and/or vocalization from the other male (Grant \& Mackintosh, 1963).

Then, during a 10 -min rest period, the three rats were removed from the enclosure and two wooden partitions forming a " $T$ " were installed, thus creating three compartments, the floor of each compartment measuring $30 \times 60 \mathrm{~cm}$. For descriptive purposes, the three compartments are here designated as $\mathbf{M}-1, \mathbf{M}-2$, and F-Only. The long axes of $M-1$ and $M-2$ were parallel to each other and the long axis of F-Only was perpendicular to the other two. Each male was placed individually in M-1 or M-2 and confined there on a body leash that, via a light chain and snap swivels, was connected to a guy wire that ran overhead the full length of the long axis of the male's compartment. The female was placed in F-Only. Two openings $(8 \times 10 \mathrm{~cm})$ connecting F-Only to M-1 or F-Only to M-2 were each closed by a ceramic block. At the outset of the mating preference test, the blocks were removed, enabling the female to move freely throughout the three compartments. Thus, during testing, the female completely controlled mating behavior because it could enter 
Table 1

Responses of Females $(\mathbf{N}=12)$ to Dominant vs. Subordinate Males

\begin{tabular}{lclccc}
\hline & Mean Time Spent & \multicolumn{4}{c}{ Mean Number of } \\
\cline { 3 - 6 } & With Male & Entries & Mounts & Intromissions & Ejaculations \\
\hline Dominant Male & 9.4 & 21.2 & 8.8 & 6.7 & .9 \\
Subordinate Male & 3.2 & 12.1 & 3.7 & 1.5 & .1 \\
Difference & $+6.2^{* *}$ & $+9.1^{* *}$ & $+5.1^{*}$ & $+5.2^{* *}$ & $+.8^{*}$ \\
Preference Ratio & $12 / 0$ & $11 / 1$ & $10 / 2$ & $11 / 0 \dagger$ & $8 / 1 \dagger \dagger$ \\
\hline
\end{tabular}

Note-Time is measured in minutes. Preference ratio is defined as the number of females interacting more with their dominant male divided by the number of females interacting more with their subordinate male.

${ }^{*} p<.05 . \quad{ }^{* *} p<.01$. TOne tied score. $\quad$ t†Three pairs of males did not ejaculate.

and leave M-1 and M-2, but neither male could leave its compartment.

Immediately after the $10-\mathrm{min}$ rest period, each female received a 40-min mating preference test, during which the experimenters recorded the number of times the female entered each male's compartment, the total time spent by the female in each male's compartment, and the number of mounts, intromissions, and ejaculations achieved by each male. Male rats are incapable of mating for some minutes following an ejaculation (Adler, 1973), and during this period, the female might have entered the other male's compartment as her second choice. To prevent this from happening, the female was confined for $5 \mathrm{~min}$ with the male that ejaculated by blocking the exit from that compartment. These 5 -min periods were included as part of the 40-min test, but they were not included as part of the time that the female spent with the male.

\section{RESULTS AND DISCUSSION}

As shown in Table 1, the 12 females exhibited a strong preference to mate with the male previously judged to be dominant. The females entered the dominant male's compartment more frequently [Wilcoxon test, $\mathrm{T}(12)=6.5, \mathrm{p}<.01]$, and they spent more time in the dominant male's compartment $[\mathrm{T}(12)=0, \mathrm{p}<.01]$. Furthermore, more mating behavior occurred in the dominant male's compartment, as shown by reliable differences in the number of mounts $[\mathrm{T}(12)=12.5$, $\mathrm{p}<.05$ ] , intromisssions [T( 11$)=0, \mathrm{p}<.01]$, and ejaculations $[\mathrm{T}(9)=4, \mathrm{p}<.05]$.

Interestingly, the difference in the amount of mating behavior exhibited by dominant vs. subordinate males virtually disappears when one takes into account the fact that the females spent more time with the dominant than with the subordinate male. For the dominant males, the number of mating responses (mounts plus intromissions, with or without ejaculation) per minute of access to the female was 1.75 . The comparable statistic for the subordinate males was 1.64 . Under present conditions, dominant males do not differ reliably from subordinate males in sexual vigor.

Taken together, the present findings and those reported by Thor and Carr (1979) suggest that success in intermale aggression enhances the fitness of male rats in two respects. First, by actively inhibiting the mating behavior of subordinates, dominant males gain uncontested access to receptive females, which constitute a limited resource (Thor \& Carr, 1979). Second, given a choice, females prefer to mate with dominant males rather than with subordinate males (present experiment). Admittedly, the second point is based upon the use of a rather unnatural technique, that is, tethering the males to limit their movements. But Calhoun (1962) and Flannelly and Lore (1977) reported that males capable of establishing a territory in a seminatural environment sometimes gain sole access to the females living in that territory.

Additional research is needed to identify the cue(s) mediating the preferences of female rats to mate with dominant males rather than with subordinates. It is interesting to note that female rats can discriminate between the odors of two individual males on the basis of their "olfactory signatures" (Carr, DeMesquitaWander, Sachs, \& Maconi, 1979). Moreover, rats can discriminate between the odors of dominant vs. subordinate males with which they have never cohabited (Krames, Carr, \& Bergman, 1969).

Alternatively, the preference by female rats to mate with dominant males rather than with subordinates may stem from behavioral differences between the two types of male (e.g., from differences in the manner in which the males copulate). If so, the difference is not likely to be simply a matter of sexual vigor. Under present testing conditions, dominant males and subordinate males do do not differ in the amount of mating behavior they exhibit per unit time of access to females.

\section{REFERENCES}

AdLER, N. T. The biopsychology of hormones and behavior. In D. A. Dewsbury \& D. A. Rethlingshafer (Eds.), Comparative psychology: A modern survey. New York: McGraw-Hill, 1973.

Calmoun, J. B. The ecology and sociology of the Norway rat (U.S. Public Health Service Publication No. 1008). Washington, D.C: U.S. Government Printing Office, 1962.

Carr, W. J., DeMegquita-Wander, M., Sachs, S. R., \& MAconi, P. Responses of female rats to odors from familiar vs. novel males. Bulletin of the Psychonomic Society, 1979, 14, 118-121.

DEwsbury, D. A. Effects of novelty on copulatory behavior: The Coolidge effect and related phenomena. Psychological Bulletin, $1981,89,464-482$.

Doty, R. L. A cry for the liberation of the female rodent: Court- 
ship and copulation in rodentia. Psychological Bulletin, 1974, 81, 149-172.

Flannelly, K. J., \& LoRe, R. Observations of the subterranean activity of domesticated and wild rats (Rattus norvegicus): A descriptive study. Psychological Record, 1977, 27, 315-329.

Grant, E. C., \& Mackintosh, J. H. A description of the social postures of some laboratory rodents. Behaviour, 1963, 21, 246-259.
Krames, L., Carr, W. J., \& Bergman, B. A pheromone associated with social dominance among male rats. Psychonomic Science, 1969, 16, 11-12.

Thor, D. H., \& CARr, W. J. Sex and aggression: Competitive mating strategy in the male rat. Behavioral and Neural Biology, 1979, 26, 261-265.

(Received for publication July $14,1982$. 